\title{
Planejamento familiar: uma questão de escolha'
}

\author{
Familiar planning: a question of the choice
}

\section{Planeamiento familiar: una cuestión de elección}

Érica da Conceição Andrade', Leila Rangel da Silva"l

\footnotetext{
${ }^{1}$ Resultado Parcial do Projeto de Pesquisa intitulado A Influência da Cultura na Adesão de Mulheres ao Planejamento Familiar.

' Residente de Enfermagem da Secretaria Municipal de Saúde do Rio de Janeiro. Membro do Núcleo de Pesquisa, Experimentação e Estudos na Área da Saúde da Mulher e da Criança (NuPEEMC). Email: ericacandrade@yahoo.com.br.

"Professora Adjunta do Departamento de Enfermagem Materno-Infantil da EEAP da UNIRIO. Coordenadora do NuPEEMC. Universidade Federal do Estado do Rio de Janeiro/RJ. Email: rangel.leila@gmail.com.
}

\section{RESUMO}

Trata-se de um estudo descritivo, realizado com mulheres participantes do grupo de planejamento familiar de dois centros municipais de saúde situados no município do Rio de Janeiro, desenvolvido em 2006 . Teve como objetivo analisar os fatores determinantes na escolha do método contraceptivo de 50 mulheres com 18 anos ou mais participantes do grupo. Os dados foram coletados por meio de entrevista semi-estruturada e observação direta. Os resultados demonstraram que o método contraceptivo mais utilizado foi o anticoncepcional oral $41(82 \%)$ e o principal fator para essa escolha foi não conhecer outros métodos. Após a prática educativa, os métodos contraceptivos de maior escolha foram o DIU 17(34\%) e a esterilização feminina 10(20\%), e o principal motivo para a escolha foi não querer mais filho. Percebe-se que houve mudança significativa nos fatores que influenciaram a escolha do método antes e após a prática educativa. O planejamento familiar deve ser um elemento primordial na prevenção primária de saúde. Para a escolha de um método contraceptivo de forma livre e informada, cada indivíduo precisa conhecer e ter acesso a todos os métodos legalmente aceitos.

Descritores: Direitos reprodutivos; Planejamento familiar; Métodos contraceptivos; Saúde da mulher; Enfermagem.

\section{ABSTRACT}

It's a descriptive study, carried through familiar planning women, in two municipal health centers, in Rio de Janeiro's city. It had as an objective analyze the determinative factors in choice of the contraceptive method (CM) in 50 familiar planning participant women with more eighteen years old. The data had been collected by interview and direct comment. The results had demonstrated that the most used CM at the moment of the interview was oral contraceptive $41(82 \%)$ and the main factor for this choice was the other methods unaware. After educative practice the women more intended contraceptive methods was the DIU $17(34 \%)$ and the feminine sterilization $10(20 \%)$ and the main reason for the choice of these methods was don't have more children. We perceived that it had significant change in factors that had influenced the method choice before and after the educative practice. The familiar planning must be a primordial element in health's primary prevention. For the contraceptive method choice in a free and informed form, each one needs to know and have access to all the legally accepted methods.

Descriptors: Reproductive rights; Familiar planning; Contraceptive methods; Women's Health; Nursing.

\section{RESUMEN}

És un estudio descriptivo, ejecutado mujeres participantes del grupo de planeamiento familiar, de dos centros municipales de salud, situado a el condado de Rio de Janeiro. Tenía como objetivo analizar los factores determinativos en la opción del método anticonceptivo (MAC) en 50 mujeres participantes del grupo con mais de dicieocho años. Los datos han sido compilados por medio de entrevista y observación. Los resultados demostraram que el MAC más usado en este momento de entrevista fue el contraceptivo oral $41(82 \%)$ y el principal factor para esta selección fue no saber otros métodos. Después de la práctica educativa el método más elegido por las mujeres fue el DIU 17(34\%) y la esterilización femenina 10(20\%) ey el principal motivo por la elección de estos métodos fue no quiere mais hijos. Nosotros percibimos que si obtenían câmbios significativos en el factores que habían influenciado el método antes y después de la práctica educativa. El planeamiento familiar debe ser um elemento primordial en la prevención primaria de la salud. Para la opción de un método anticonceptivo en una forma libre y informada, cada individuo necesita conocer y tener acceso a todos legalmente aceptados.

Descriptores: Derechos reproductivos; Planeamiento familiar; métodos anticonceptivos; Salud de la Mujer; Enfermeria. 


\section{NTRODUÇÃO}

O planejamento familiar deve ser um elemento primordial na prevenção primária de saúde, que mediante estratégias individuais e coletivas utilizadas pelos profissionais de saúde orientam as pessoas que buscam tais serviços, oferecendo-lhes informações necessárias para a escolha e uso efetivo dos métodos contraceptivos que melhor se adaptem às condições atuais de saúde. Este, compreendido como o direito básico de cidadania e que deve ser tratado dentro do contexto dos direitos sexuais e reprodutivos, garantindo ao indivíduo a possibilidade de regular a fecundidade e decidir livre e responsavelmente por ter ou não filhos. Quando tê-los, ter acesso à informação, educação e serviços de planejamento familiar, exercer a sexualidade plena e realizar tratamento da infertilidade ${ }^{(1-2)}$

O processo de escolha informado na regulação da fecundidade baseia-se nos princípios de proporcionar bem-estar às pessoas, quanto à sua autonomia, expectativas, necessidades e poder de decisão ${ }^{(3)}$. Porém, as atividades de planejamento familiar nem sempre tiveram este caráter, pois nos anos $60 \mathrm{com}$ o aumento desordenado da população e difusão da teoria neomaltusiana foram desenvolvidas políticas de controle da natalidade, promovendo a criação de programas verticais de planejamento familiar. Esses programas tinham como objetivo captar um número máximo de novas usuárias de métodos de alta eficácia, não objetivando a melhoria da atenção à saúde da mulher, e nem a qualidade de vida ${ }^{(4)}$.

No Brasil, nesta mesma época, os programas de planejamento familiar foram constituídos exclusivamente por Organizações NãoGovernamentais (ONG), como por exemplo, a Sociedade Civil Bem-Estar Familiar no Brasil, a primeira entidade privada com este caráter. Neste período, pela falta de programa oficial e de autorização explícita, essa atividade não foi privilegiada nas ações de saúde, assim como o acesso a alguns métodos tornou-se difícil, mesmo nas consultas privadas. Todos os programas relativos à saúde da mulher limitavam-se às demandas relativas à gravidez e ao parto ${ }^{(4-5)}$.

Essa situação permeou toda essa fase, quando, por força dos movimentos feministas e da nova cultura instalada devido à inserção da mulher no mercado de trabalho, exigiu-se do governo um compromisso transparente com a saúde reprodutiva, para adoção de uma política contraceptiva clara ${ }^{(4)}$.

As mulheres organizadas reivindicaram, portanto, sua condição de sujeitos de direito, com necessidades que ultrapassavam o ciclo gravídicopuerperal, necessitando de ações que thes proporcionassem a melhoria das condições sociais, econômicas, culturais e afetivas ${ }^{(5)}$.
No seio desse novo pensar, juntamente com as reivindicações do movimento feminista e da sociedade civil como um todo, foi criado em 1984, o Programa de Assistência Integral à Saúde da Mulher. Esse teve como diretriz a reorganização da assistência à mulher, tendo como princípio a atenção global à saúde desta população, contemplando todas as fases que compreendem o seu ciclo da vida. Ciclo este caracterizado por intensas modificações necessitando assim de atenção especial. Dentre suas ações, temos como uma das atividades básicas o planejamento familiar ${ }^{(3,5)}$.

Todas essas ações possuem como objetivo a promoção, prevenção e recuperação da saúde e pressupõe uma prática educativa, a fim de garantir as usuárias conhecimentos necessários a um maior controle sobre sua saúde ${ }^{(1)}$.

A ação educativa em saúde tornou-se uma das atividades inerentes à enfermagem, desempenhada em toda sua área de atuação, que deve ser desenvolvida em todos os níveis de atenção à saúde. A respeito da prática educativa, os profissionais de saúde e a enfermagem devem empenhar-se nas informações precisas aos usuários, para que tenham conhecimento sobre todas as alternativas de anticoncepção e possam participar livre e ativamente da escolha do método contraceptivo(1).

Esta combinação pressupõe oportunidades que favoreçam a promoção da saúde e não somente a transmissão de conteúdos, comportamentos e hábitos, mas também, a adoção de práticas educativas que busquem de forma crítica e reflexiva, considerando as particularidades de cada ser, a troca de experiências no âmbito grupal ${ }^{(2-4)}$.

Pensando em todas essas questões que envolvem a saúde reprodutiva da mulher elegeu-se como objeto de estudo os fatores determinantes na escolha do método contraceptivo por mulheres participantes do grupo de planejamento familiar.

Considerando como fundamental para o direcionamento deste estudo foram construídas as seguintes questões norteadoras: A individualidade da mulher é respeitada no momento da escolha do método contraceptivo? Que fatores interferem na escolha do método pelas mulheres participantes do grupo de planejamento familiar?

Tendo em vista as questões concernentes ao planejamento familiar, o estudo teve como objetivo analisar os fatores que são determinantes na escolha do método contraceptivo em mulheres participantes do grupo de planejamento familiar.

\section{METODOLOGIA}

Trata-se de um estudo descritivo, com abordagem quantitativa. Participaram do estudo cinqüenta mulheres seguindo os seguintes critérios de inclusão: a) participar do grupo de planejamento familiar; b) ter dezoito anos ou mais de idade. A 
pesquisa ocorreu em dois Centros Municipais de Saúde, um situado na Área Programática (AP) 2.1 (Zona Sul) e o outro na AP 1.0 (Zona do Centro) do município do Rio de Janeiro. A coleta de dados foi realizada no período de 12 de janeiro a 19 de abril de 2006, e foram desenvolvidas durante os grupos de planejamento familiar. Foi feita a observação de quatro grupos, estes foram constituídos basicamente de mulheres sendo a presença masculina em número bastante reduzida.

Em ambas as instituições, as ações educativas em planejamento familiar consistiram em três encontros, com periodicidade mensal, onde foram tratadas questões relativas ao conhecimento do corpo, sexualidade, informação e discussão sobre vários métodos contraceptivos. Na última reunião houve uma consulta individual onde cada mulher escolheu o MAC que pretendia adotar.

No centro municipal situado na AP 2.1 estas atividades foram desenvolvidas por uma equipe multidisciplinar composta por assistente social, enfermeira e médica, já no outro centro municipal em questão, as atividades foram desenvolvidas apenas pela assistente social.

As entrevistas foram realizadas no último encontro de cada grupo, no espaço do Centro Municipais de Saúde. Para a coleta de dados foi construído um roteiro semi-estruturado para obtenção dos dados socioeconômicos, ginecoobstétrico e o conhecimento e utilização dos métodos contraceptivos pré e pós grupo de planejamento familiar. Utilizou-se também a observação direta que permitiu o pesquisador participar ativamente do grupo, possibilitando tecer suas considerações e reflexões baseadas nos encontros, permitindo uma maior apreensão dos significados emitidos pelas participantes do estudo( ${ }^{(6)}$. As entrevistas foram gravadas em fita K-7 e transcritas posteriormente.

O estudo foi aprovado pelo Comitê de Ética em Pesquisa do Hospital Universitário Gaffrée e Guinle, memorando CEP/no129/2005. A participação das mulheres no estudo foi voluntária, mediante a assinatura de Termo de Consentimento Livre e Esclarecido - Resolução 196/96 do CNS, sendo garantido o anonimato e sigilo, o respeito à privacidade e intimidade e a sua liberdade de declinar sua participação no momento que desejasse.

$\mathrm{Na}$ fase de exploração dos dados fez-se a codificação do material, para isso, numeraram-se os roteiros das entrevistas de 01 a 50 e para cada dia da coleta foi determinada uma letra. Na fase de interpretação e tratamento, os resultados brutos foram tratados de maneira a serem significativos e válidos. Utilizou-se estatística simples como freqüência absoluta $(n)$ e percentual (\%), para a construção de tabelas, a fim de consolidar as informações fornecidas para análise.

\section{RESULTADOS}

\section{Perfil sócio-econômico e reprodutivo do grupo de mulheres}

Na amostra estudada, mais da metade das mulheres tinha idade entre 25 a 34 anos 29 (58\%). Em relação ao estado conjugal, 13 (26\%) estavam solteiras, 12 (24\%) casadas e 25 (50\%) viviam em união consensual.

As mulheres moravam em sua maioria na zona do Centro (AP 1.0) do município do Rio de Janeiro 32 $(64 \%)$, em casa própria $33(66 \%)$, possuíam o ensino fundamental incompleto $23(46 \%)$ e não realizavam trabalho remunerado 23 (46\%). Das que trabalhavam, 6 (12\%) eram empregadas domésticas. A grande maioria das entrevistadas 36 (72\%) referiu renda familiar de $1 / 2$ a 2 salários mínimos. Quanto a religião 40 (80\%) das entrevistadas afirmaram ter vínculo com alguma, sendo que 25 (50\%) referiram ser católicas, 13 (26\%) evangélicas e 2 (4\%) espíritas.

Em relação à idade da primeira relação sexual $30(60 \%)$ ocorreu entre 15 a 19 anos, sendo 11 $(22 \%)$ ocorreu entre 10 e 14 anos. A maioria 41 $(82 \%)$ declarou ter parceiro fixo. Quase todas as mulheres já tinham engravidado alguma vez 49 (98\%). Dessas, 37 (74\%) referiram duas ou mais gestações e a mesma quantidade terem tido parto normal. Um pouco mais da metade 28 (56\%) relataram ter dois ou mais filhos, e quase todas 48 (96\%) declararam não terem tido filhos natimortos. Das entrevistadas $20(40 \%)$ das entrevistadas referiram ter tido aborto, destas 10 (41,7\%) relataram ter sido provocado.

Dentre as mulheres entrevistadas, a maioria 43 (86\%) não participaram de prática educativa anteriormente e todas já utilizaram ou estavam utilizando algum método contraceptivo, 4 (8\%) estavam grávidas ou não utilizavam método contraceptivo.

\section{Conhecimento, uso e fatores para a escolha dos métodos contraceptivos antes do grupo de planejamento familiar}

Em relação ao conhecimento dos métodos contraceptivos, pode-se verificar na Tabela 1 a distribuição das respostas das entrevistadas sobre o método contraceptivo e fatores que influenciaram a escolha do método antes da participação no grupo de planejamento familiar. 
Tabela 1: Distribuição do número $(n)$ e do percentual (\%) das entrevistadas segundo o método contraceptivo e fatores que influenciaram a escolha do método antes da participação no grupo de planejamento familiar (PF), Rio de Janeiro, 2006.

\begin{tabular}{|c|c|c|}
\hline Método contraceptivo atual & $\mathbf{n}$ & $\%$ \\
\hline Condom masculino & 16 & 32 \\
\hline Anticoncepcional oral & 17 & 34 \\
\hline Anticoncepcional Injetável & 2 & 4 \\
\hline DIU & 2 & 4 \\
\hline \multicolumn{3}{|l|}{ Métodos Associados } \\
\hline Diafragma+espermicida & 1 & 2 \\
\hline Anticoncepcional oral+condom masculino & 2 & 4 \\
\hline DIU+condom masculino & 1 & 2 \\
\hline Anticoncepcional Injetável+condom masculino & 1 & 2 \\
\hline Nenhum & 4 & 8 \\
\hline Grávida & 4 & 8 \\
\hline $\begin{array}{rc}\text { TOTAL } \\
\end{array}$ & 50 & 100 \\
\hline \multicolumn{3}{|c|}{ Fatores que influenciaram a escolha do MAC antes da participação no grupo PF* } \\
\hline Dá reação & 16 & 32 \\
\hline O marido não gosta & 3 & 6 \\
\hline Por não conhecer outros métodos & 17 & 34 \\
\hline Mais prático/fácil & 15 & 30 \\
\hline Por influência do médico & 9 & 18 \\
\hline Fácil aquisição & 6 & 12 \\
\hline Mais seguro & 12 & 29 \\
\hline Não faz mal à saúde & 14 & 8 \\
\hline Não adequação ao uso do método & 8 & 16 \\
\hline Fase da vida & 6 & 12 \\
\hline Por indicação de outra pessoa & 2 & 4 \\
\hline Previne doenças & 2 & 4 \\
\hline Outros & 3 & 6 \\
\hline
\end{tabular}

*A soma total excede $n=50$, por haver superposição de respostas.

Em relação ao conhecimento dos métodos contraceptivos, o anticoncepcional oral, o condom e o DIU foram os mais citados, respectivamente, 49 $(98 \%), 46(92 \%)$ e 42 (84\%). Mesmo após a participação em grupos de orientação ao planejamento familiar, os métodos naturais foram os menos citados 8 (16\%).

Quando perguntadas sobre quais foram os métodos contraceptivos já utilizados em algum momento de sua vida, os mais freqüentes foram anticoncepcional oral 41 (82\%), condom 36 (72\%) e anticoncepcional injetável $10(20 \%)$. Os métodos que estavam sendo mais utilizados pelas mulheres no momento da realização da entrevista foram: anticoncepcional oral 17 (34\%) e condom 16 (32\%). As principais razões para esta escolha foram: "não conhecer outro método" 17 (34\%), "outros MAC faziam mal e/ou davam reação" 16 (32\%) e "mais prático e/ou mais fácil" 15 (30\%) (Tabela 1).

Quando se relacionou o método contraceptivo utilizado no momento da pesquisa e o estado conjugal, entre as solteiras um pouco mais de um quarto $3 \quad(27,3 \%)$ estavam utilizando anticoncepcional oral e a mesma quantidade não estava usando método contraceptivo. Entre as mulheres casadas $7(58,3 \%)$ usavam condom e 4
$(33,3 \%)$ usavam anticoncepcional oral. Das mulheres em união consensual, 10 (37\%) usavam anticoncepcional oral e 7 (26\%) condom.

Em todas as faixas etárias o método contraceptivo mais usado foi o anticoncepcional oral $17(34 \%)$ e o condom 16 (32\%). Ao relacionarmos o método contraceptivo atual com a escolaridade e o número de filhos, este segue a mesma tendência da faixa etária.

\section{Conhecimento e auto-percepção sobre o grupo de planejamento familiar}

Entre as mulheres, 20 (40\%) referiram terem tido conhecimento do grupo de planejamento familiar através "amiga/vizinha/parente/marido/conhecido" e 17 (34\%) através do "médico". Dentre as razões para participar do grupo foram expressos os seguintes motivos: "conhecer outros métodos" 23 (46\%), "fazer laqueadura" $11(22 \%)$ e "colocar o DIU" 10 (20\%)

Após ter assistido à ação educativa observou-se a distribuição percentual das entrevistadas em relação à sua auto-percepção. Constatou-se que quase todas as mulheres $48(96 \%)$ relataram ter tido liberdade de escolha na eleição do método. 
Fatores para escolha do método contraceptivo após o grupo de planejamento familiar

Quanto se analisa os fatores que influenciam a escolha dos métodos contraceptivos após o planejamento familiar observa-se que, estes são variáveis de acordo com a experiência das mulheres, conforme está ilustrado na Tabela 2.

Tabela 2: Distribuição do número $(n)$ e do percentual (\%) das entrevistadas segundo o método contraceptivo e fatores que influenciaram a escolha do método após participação no grupo de planejamento familiar (PF), Rio de Janeiro, 2006.

\begin{tabular}{|c|c|c|}
\hline Método contraceptivo pretendido & $\mathbf{n}$ & $\%$ \\
\hline Condom masculino & 2 & 4 \\
\hline Anticoncepcional oral & 6 & 12 \\
\hline Anticoncepcional Injetável & 7 & 14 \\
\hline DIU & 17 & 34 \\
\hline Esterilização Feminina & 10 & 20 \\
\hline Vasectomia & 1 & 2 \\
\hline \multicolumn{3}{|l|}{ Métodos associados } \\
\hline Diafragma+espermicida & 1 & 2 \\
\hline Anticoncepcional oral+condom masculino & 3 & 6 \\
\hline Esterilização Feminina+condom masculino & 2 & 4 \\
\hline Anticoncepcional Injetável+condom masculino & 1 & 2 \\
\hline $\begin{array}{lc} & \text { TOTAL } \\
\end{array}$ & 50 & 100 \\
\hline \multicolumn{3}{|c|}{ Fatores que influenciam a escolha do mac pretendido* } \\
\hline Os outros métodos dão reação & 16 & 32 \\
\hline O marido não quer usar camisinha & 3 & 6 \\
\hline Não querer ter mais filho & 23 & 46 \\
\hline Mais seguro & 24 & 24 \\
\hline Mais prático/fácil & 18 & 36 \\
\hline Risco para a saúde & 2 & 4 \\
\hline Dificuldade de reversão do método & 2 & 4 \\
\hline Não faz mal à saúde & 2 & 4 \\
\hline Fase da vida & 4 & 8 \\
\hline Não adequação ao MAC & 9 & 18 \\
\hline Fácil aquisição & 3 & 6 \\
\hline Outros & 4 & 8 \\
\hline
\end{tabular}

*A soma total excede $n=50$, por haver superposição de respostas.

As mulheres foram questionadas, após a prática educativa, em relação ao método contraceptivo que pretendiam usar, o mais citado foi DIU 17 (34\%), seguido da esterilização feminina $10(20 \%)$ e o anticoncepcional injetável 7 (14\%) (Tabela 2). Ao relacionarmos o método contraceptivo atual com o pretendido 39 (78\%) mudaram de método, destas, 19 (49\%) optaram pelo mesmo método pelo qual pretendiam trocar quando procuraram o grupo de planejamento familiar.

Dentre as mulheres, as principais razões para a escolha do método contraceptivo pretendido foi "não querer mais filho" 23 (46\%), 18 (36\%) consideraram como método "mais prático e/ou mais fácil", 16 (32\%) relataram que "outros métodos dão reação" e as demais 12 (24\%) consideraram como método "mais seguro" (Tabela 2). Quando relacionamos o método contraceptivo pretendido com o estado conjugal, surge uma diferença em relação às mulheres que apresentam união consensual 10 $(37 \%)$ e as solteiras $2(18 \%)$ quanto à pretensão pela esterilização feminina. Ao relacionarmos a idade com o método contraceptivo pretendido, verifica-se a escolha da esterilização feminina em 9 (69,2\%) das mulheres na faixa etária entre 25 a 29 anos e 11 $(68,7 \%)$ na faixa etária $30-34$ anos. A maioria das mulheres $30(60 \%)$ optou por um MAC reversível.

Ao se cruzar o MAC pretendido com a escolaridade, percebe-se o predomínio dos métodos reversíveis em todos os níveis de escolaridade, em especial o DIU, que apresentou percentual médio de $38,8 \%$. Relacionando o MAC pretendido com o número de filhos percebe-se o predomínio de métodos reversíveis entre as mulheres com até dois filhos 33 (94,3\%), destes 14 (40\%) optou pelo DIU, seguido do anticoncepcional oral $9(22,8 \%)$ e do anticoncepcional injetável $8(20 \%)$. Dentre as mulheres com até dois filhos, $3(8,6 \%)$ optaram pela esterilização feminina. A partir do segundo filho, o percentual de métodos reversíveis diminui, passando para $5(33,3 \%)$ e a esterilização feminina aumenta para $9(60 \%)$ e $1(6,7 \%)$ vasectomia. 


\section{O grupo de planejamento familiar}

Em relação ao grupo de planejamento familiar, foi perguntado o que foi mais importante na participação. Mais da metade referiu "conhecer os métodos" 30 (60\%), seguido de "poder tirar dúvidas" $9(18 \%)$ e "forma como é passada as informações" 8 (16\%). A totalidade das mulheres referiram alto grau de satisfação quanto a forma com que foram realizados os encontros e a utilização de materiais didáticos com informações claras e precisas.

Em relação à prática educativa realizada nos dois centros municipais de saúde foram feitas várias observações em ocasiões distintas. As reuniões observadas duraram de uma hora e meia a duas horas e o número de participantes na unidade situada na AP 2.1 variou de 15 a 24 pessoas e na unidade da AP 1.0 de 10 a 15. Em cada grupo houve em média dois homens acompanhando as esposas, sendo que em um dos grupos havia um homem que por iniciativa própria compareceu a reunião.

Em ambas as instituições, as profissionais que estavam realizando a prática educativa procuraram estabelecer uma relação cordial com as mulheres, mostrando-se acessíveis e simpáticas. Elas iniciavam a prática identificando o perfil das mulheres através de uma rápida dinâmica e o primeiro tema a ser tratado foi sobre o conhecimento do corpo feminino e masculino, neste momento foi falado em algumas reuniões sobre sexualidade e logo em seguida sobre os métodos de barreira. Vale ressaltar que em poucas reuniões falaram sobre o que é planejamento familiar, e ao término do grupo quando as mulheres foram questionadas referiram "prevenir de ficar grávida sem estar preparada" 21 (42\%), seguido por "conhecer o corpo" 16 (32\%), "planejar a família/quantos filhos cada casal quer" 15 (30\%), sendo que 3 (6\%) disseram "não saber informar".

Foram utilizados pelos profissionais três recursos para ilustrar as reuniões, facilitando a compreensão das pessoas presentes: o álbum seriado que mostrava a anatomia feminina e masculina e os métodos contraceptivos; amostras dos métodos contraceptivos, que circulavam entre as participantes e próteses de silicone dos órgãos genitais feminino e masculino. Durante as reuniões foi dada oportunidade para que as mulheres fizessem perguntas, que foram respondidas adequadamente. Em seguida, os profissionais informavam quais os métodos disponíveis nos Centros de Saúde, reforçando sempre a dificuldade de acesso para a esterilização feminina.

\section{SCUSSÃO}

Os resultados da presente pesquisa demonstram que houve importantes mudanças no uso e nos fatores que determinaram a escolha do método contraceptivo antes e após a prática educativa. A maioria das mulheres que participaram do grupo já utilizava algum MAC sendo o mais citado o anticoncepcional oral, uma das principais razões para esta escolha foi o desconhecimento de outros métodos e as reações que outros métodos contraceptivos faziam, o que demonstra a desinformação sobre os meios de regulação da fecundidade disponíveis e seus possíveis efeitos adversos.

A prevalência de determinados métodos como, por exemplo, o anticoncepcional oral, pode indicar a deficiência dos serviços de planejamento familiar que foram desenvolvidos, o que leva a reflexão sobre alguns pontos. Essa insuficiência pode estar vinculada a vários fatores relacionados ao serviço de saúde, aos usuários e profissionais que determinam a qualidade da atenção em planejamento familiar, tais como: a possibilidade de escolha livre e informada, acesso e oferta satisfatória de MAC, competência técnica dos profissionais que realizam as atividades educativas, de aconselhamento e clínicas; qualidade da comunicação interpessoal e o acesso aos serviços de saúde (3-4,7-8). $^{\text {. }}$.

Estudo realizado em Maringá, com 284 mulheres cadastradas no programa de saúde da família com idade entre 35-49 anos, constatou a prevalência do uso de determinados métodos como o anticoncepcional oral $50,3 \%$ e do condom $28,1 \%$. No grupo de usuárias de pílula, 23,8\% interrompeu o uso do método devido a presença de efeitos colaterais. Em 74\% dos casos, o uso do anticoncepcional oral foi orientado por um profissional da área de saúde ${ }^{(8)}$. Outro estudo realizado com 295 universitários, ingressantes de uma universidade do Estado de São Paulo, com idade menor ou igual a 19 anos, verificou um conhecimento deficiente e prática incorreta do uso da pílula anticoncepcional, principalmente em como lidar com os efeitos colaterais ou com situações inesperadas ${ }^{(9)}$.

Segundo $\operatorname{Costa}^{(4)}$, "No Brasil, há uma polarização do uso de contraceptivos, na qual a pílula e a esterilização cirúrgica imperam. É desejável a reversão dessa situação, resultante, dentre outros aspectos, da indisponibilidade de tecnologias alternativas." O autor afirma que esta reversão na disponibilidade de métodos, seria importante para se garantir a autonomia na escolha do $\mathrm{MAC}^{(4)}$.

Quanto ao conhecimento dos MAC, as tecnologias contraceptivas hormonais entre outras tecnologias contraceptivas foram os mais citados, mostrando que os naturais são pouco divulgados e estimulados nas práticas educativas, já que estes requerem um maior conhecimento do corpo e disciplina, possuindo uma taxa elevada de falha ${ }^{(10-11)}$. Estudo feito em municípios do Brasil, constatou que há alta concentração da oferta de pílula em relação a oferta de outras tecnologias alternativas ${ }^{(4)}$.

Nos grupos observados, uma das hipóteses a serem levantadas para a maior escolha de métodos 
reversíveis é que, haveria maior acesso a contraceptivos incluindo melhores informações sobre estes métodos. Outra hipótese é que, nesses grupos, haveria maiores obstáculos ao acesso à esterilização. A segunda hipótese parece ser a mais viável, já que no decorrer das práticas educativas, ficou explícito que, dependendo do método de escolha, este não seria viável devido à indisponibilidade do MAC no serviço de saúde, influenciando assim na escolha do método pelas mulheres. Estudo feito por Carvalho(12), com mulheres que tiveram seu primeiro filho em 1985, em Campinas, São Paulo revelou que a escolha das mulheres pela laqueadura tubária, representava uma demanda insatisfeita de anticoncepção e mostrou que as mesmas dispunham de poucas opções e enfrentavam dificuldades para ter acesso a métodos contraceptivos.

Isso demonstra que, apesar dos serviços oferecerem planejamento familiar, estes não estão sendo realizados de forma apropriada, visto que não estão ofertando todos os métodos, prejudicando a qualidade da atenção em planejamento familiar prestada, diminuindo a adesão e eficácia do serviço.

A qualidade da atenção em planejamento familiar tem sido reconhecida como fator fundamental para o início e a continuidade do uso de MAC, especialmente entre mulheres com menor nível educacional. A grande variedade de MAC ofertada, juntamente com a qualidade da comunicação interpessoal e da orientação estariam dentro dos padrões ideais para assegurar a liberdade de escolha(3) $^{(3)}$ A qualidade da atenção em planejamento familiar é reconhecido como fator primordial para o início e a continuidade do uso de métodos contraceptivos $^{(5)}$.

Outros fatores a serem observados foram a prevalência de métodos de uso feminino e a escassa participação masculina na contracepção, evidenciado nas relações de gênero, apontando para o papel social desempenhado pelo homem em uma sociedade historicamente patriarcal, que impõe à mulher a responsabilidade pela contracepção, isso é comprovado quando constatamos que a maioria dos métodos disponíveis no mercado é de domínio feminino $^{(11,13-14)}$. Pesquisa realizada com 16 mulheres em Curitiba/PR destacou a violência de gênero não só pela sua freqüência, mas pelos efeitos produzidos que torturam a vida e a saúde sexual e reprodutiva das mulheres, tornando-se um empecilho para o exercício dos direitos sexuais e reprodutivos ${ }^{(11)}$.

O uso de condom reduziu de $40 \%$ para $16 \%$ depois da participação no grupo, queda significativa, mostrando possível deficiência das práticas educativas na área do planejamento familiar ao incluir nas suas ações, informações sobre medidas de proteção contra DST/AIDS, conforme preconizado pelo Ministério da Saúde ${ }^{(1,10)}$. Em estudo realizado em uma universidade do Estado de São Paulo, 46,1\% dos adolescentes disseram que o preservativo não interferia na relação sexual, sendo que $23,1 \%$ relataram que ocorre diminuição do prazer sexual, mostrando ser necessário discutir e ressaltar a associação do preservativo ao prazer como resultado da segurança que eles oferecem não somente relacionada a gravidezes indesejadas, mas também prevenção de DSTs e AIDS ${ }^{(9)}$.

Contrariando outros estudos, dentre os métodos reversíveis, após participação no grupo de planejamento familiar o DIU foi o MAC mais pretendido entre as mulheres. Isso pode ser devido a maneira como foram fornecidas as informações sobre este método pelos profissionais de saúde ou pela dificuldade de acesso a determinados MAC. Estudos evidenciam o anticoncepcional oral e a esterilização feminina, como métodos mais escolhidos e utilizados pelas mulheres ${ }^{(4,8)}$. Outra pesquisa revelou que o conhecimento inadequado sobre qualquer método contraceptivo pode ser um motivo de resistência à adesão e uso desse método, da mesma forma que o alto nível de conhecimento não determina mudanças de comportamento ${ }^{(15)}$.

Também foi observado que grande parte das mulheres teve início precoce da vida sexual, essa antecipação gera um maior tempo de exposição à concepção, o que pode ter influenciado na escolha por métodos mais seguros, dado o início e o desejado término precoce da vida reprodutiva ${ }^{(10,16-17)}$. A desvinculação da mulher do papel clássico e exclusivo de ser mãe e sua entrada no mercado de trabalho ampliou seu desejo por controlar a fecundidade e praticar a anticoncepção, o que desvincula a maternidade da vivência plena de sua vida sexual ${ }^{(4)}$.

Depois da prática educativa, um dos principais motivos para escolha do MAC pretendido foi "não querer mais filho". Diante do exposto surge a seguinte consideração: quase todas as mulheres já tinham feito uso de algum MAC ou estavam utilizando algum método contraceptivo antes de participarem do grupo de planejamento familiar. Mesmo assim afirmaram o desejo por não engravidar, o que evidenciou possível falha ou não adequação aos MAC utilizados anteriormente. Dessa forma, pode-se afirmar que essas mulheres não tinham total conhecimento dos métodos utilizados, fazendo uso destes sem buscarem esclarecimento e apoio por profissionais qualificados, ratificando a importância dos serviços de planejamento familiar.

Outro fator que parece ter grande influência na escolha de métodos definitivos pelas mulheres é o número de filhos, pois a partir do segundo filho o percentual do uso de métodos reversíveis cai de 33 $(94,3 \%)$ para $5(33,3 \%)$ e os métodos definitivos passam de $3(8,6 \%)$ para $10(66,7 \%)$, fato que pode ser confirmado ao se levar em consideração os principais fatores para a escolha do MAC pretendido, que em geral foi não querer mais filhos e, portanto a 
segurança do método. Isso pode significar um rompimento com a vida reprodutiva e um desejo de vivenciar a sexualidade de forma prazerosa, saudável e despreocupada ${ }^{(4,13)}$.

O estudo evidenciou que a grande preocupação das mulheres ao elegerem um MAC não esta relacionada aos possíveis efeitos colaterais, mas a sua eficácia, pois isto pode constituir um dos principais fatores para a descontinuação do método ${ }^{(3,8,15)}$.

O profissional de saúde deve atentar para este aspecto, desenvolvendo métodos na tentativa de mobilizar a atenção das mulheres para este fato no momento que elas solicitam um determinado MAC.

Dentre as mulheres houve uma grande taxa de abortos provocados, fato que evidencia a grande ocorrência de gravidez não desejada. A melhor estratégia para diminuir esse número, é tornar os métodos contraceptivos disponíveis e acessíveis. A elevada taxa de aborto provocado pode ter influenciado na decisão pela esterilização e por métodos reversíveis mais seguros ${ }^{(14)}$. De acordo com estudo a anticoncepção tem papel incomparável e seu uso de forma inadequada favorece a ocorrência de vários agravos, como a gravidez indesejada, gravidez na adolescência, abortamentos ilegais e aumento na mortalidade materna ${ }^{(8)}$.

Em relação à prática educativa, de modo geral, os resultados apresentados indicam que as mulheres sentiram-se bastante livres para escolher o MAC e todas referiram satisfação com a forma com que as informações foram dadas e o conteúdo. A continuidade do uso de MAC está relacionada à satisfação das mulheres com o mesmo e à sua percepção quanto à suficiência das informações recebidas quando optaram pelo método ${ }^{(3,7)}$. Esse fato é um ponto relevante, já que a principal razão identificada pelas mulheres para procurar o grupo foi conhecer outros métodos. As práticas de educação em saúde e sexualidade devem ser entendidas como instrumentos disseminadores de informações para fortalecimento da autonomia das mulheres e do casal $^{(4)}$.

Os profissionais de saúde devem defender e articular o direito de cada mulher à escolha pessoal e a liberdade nas decisões referentes a seu corpo e suas opções reprodutivas, para isso elas devem ser bem informadas sobre alternativas de concepção e anticoncepção para alcançar tais metas ${ }^{(4,7)}$. Isso mostra que a prática educativa conseguiu atender satisfatoriamente as inquietações e a individualidade destas mulheres.

Ao se analisar o conhecimento das mulheres entrevistadas nesta pesquisa sobre o que é planejamento familiar no contexto dos direitos reprodutivos e sexuais, se percebe uma apreensão errônea sobre esta ação, já que muitas referiram ser "o conhecimento do corpo" e "saber como não ter filhos". Esse fato que chamou a atenção, pois a maioria das mulheres associou o planejamento familiar à forma de reduzir o número de filhos, visto que muitas mulheres buscam o grupo com a finalidade de anticoncepção, devido ao distanciamento dos serviços de apoio à concepção(7). Esse aspecto deve ser repensado, pois um dos papéis desta ação educativa é instrumentalizar as mulheres, dando-Ihes subsídios para o exercício consciente do seu direito à saúde reprodutiva e sexual. "Direitos que buscam a interação de direitos sociais, como os direitos à saúde, à educação e ao trabalho, com os direitos individuais à vida, à igualdade, à liberdade, a inviabilidade da intimidade"(11). De acordo com pesquisa(4) $^{(4) i t a ~ e m ~ m u n i c i ́ p i o s ~ b r a s i l e i r o s, ~ 72,9 \% ~}$ dos municípios não realizam assistência aos casos de infertilidade, ação esta que deveria constar no conjunto de atividades do planejamento familiar.

Outro fato observado é que, das mulheres que procuraram o grupo já com o MAC pretendido em mente, optaram pelo mesmo método que pensavam em escolher quando procuram o serviço. Segundo estudo $^{(3)}$ feito com usuárias de um serviço de saúde, quase todas as mulheres chegaram ao ambulatório já com o MAC escolhido, poucas mudaram de método. De acordo com o autor referido, este fato pode ser entendido no sentido que as mulheres utilizavam o conteúdo recebido na prática educativa como uma espécie de legitimador do que já tinham em mente. Esses resultados levam a reflexão sobre qual o papel das práticas educativas, já que as mulheres chegam ao serviço com pré-concepções sobre os métodos contraceptivos e acabam escolhendo o mesmo método que queriam quando iniciaram no grupo de planejamento familiar.

\section{CONCLUSÕES}

Dentro deste contexto, para escolher um método contraceptivo de forma livre e informada, cada indivíduo precisa conhecer e ter acesso a todos os métodos contraceptivos cientificamente comprovados e disponíveis, adotando aquele que seja mais adequado às suas particularidades e condições de vida.

As informações analisadas no presente estudo permitiram apresentar como fator determinante o desconhecimento de métodos para contracepção, influenciando diretamente na qualidade e escolha do MAC, interferindo desta forma no pleno exercício à saúde sexual e reprodutiva.

Após a participação no grupo de planejamento familiar a maioria das mulheres elegeu como métodos mais seguros - DIU e esterilização feminina - como forma de garantir a regulação da fecundidade.

Percebe-se que a prática educativa não foi suficiente para influenciar as concepções dessas mulheres devido à falta de informação e acesso a 
determinados MAC, das distorções e desigualdades de gênero, que incumbe de forma solitária a responsabilidade pela contracepção, mostrando que a assistência em saúde reprodutiva, continua insuficiente e a garantia de acesso e informação a todos os métodos contraceptivos ainda não se tornou realidade.

Diante disso, percebe-se que apenas o acesso e informação sobre os métodos não é suficientes para o fornecimento de um serviço de planejamento familiar de qualidade. Faz-se necessário que todos os profissionais de saúde, em especial a equipe de enfermagem, considerem a individualidade de cada mulher dado que cada uma possui sua história de vida, e essas características são resultantes das influências sofridas pelo meio físico e cultural em que está inserida, pelas suas condições econômicas e pelos bens sociais aos quais possuem direito, ao viver em uma sociedade politicamente organizada como o Brasil.

\section{REFERÊNCI AS}

1. Secretaria de Políticas de Saúde; Ministério da Saúde. Assistência em planejamento familiar: manual técnico. Brasília (Brasil): Ministério da Saúde; 2002.

2. Zampieri MFM, Nascimento MGP. Planejamento familiar e métodos anticoncepcionais. In: Zampieri MFM, Garcia O, Boehs Al, Verdi M, editores. Enfermagem na atenção primária à saúde da mulher. 2nd ed. Florianópolis: UFSC/NFR; 2005.

3. Osis MJD, Duarte GA, Crespo ER, Espejo X, Pádua KS. Escolha de métodos contraceptivos entre usuárias de um serviço público de saúde. Cad. Saúde Pública. 2004; 20(6) : 1586-94.

4. Costa AM, Guilhem D, Silver LD. Planejamento familiar: a autonomia das mulheres sob questão. Rev. Bras. Saude Mater. Infant. 2006;6(1): 75-84.

5. Ministério da Saúde; Secretaria de Atenção à Saúde, Departamento de Ações Programáticas Estratégias. Área Técnica de Saúde da Mulher. Política nacional de atenção integral à saúde da mulher: princípios e diretrizes. Brasília: Ministério da Saúde; 2004.

6. Polit DF. Fundamentos da pesquisa em enfermagem. 5th ed. Porto Alegre: Artes Médicas; 2004.

7. Moura ERF, Silva RM. Informação e planejamento familiar como medidas de promoção da saúde. Ciênc. saúde coletiva. 2004;9(4): 1023-32.

8. Souza JMM, Pelloso SM, Uchimura NS, Souza F. Utilização de métodos contraceptivos entre as usuárias da rede pública de saúde do município de Maringá-PR. Rev. Bras. Ginecol. Obstet. 2006; 28(5):271-7.

9. Alves AS, Lopes MHBM. Conhecimento, atitude e prática do uso de pílula e presertivo entre adolescentes universitários. Rev Bras Enferm. 2008; 61(1): 11-7.
10. Belo MAV, Silva JLP. Conhecimento, atitude e prática sobre métodos anticoncepcionais entre adolescentes gestantes. Rev. Saúde Públ. $2004 ; 38(4): 479-87$.

11. Souza KV, Tyrrell MAR. Os fatos \& atos relacionados ao (difícil) exercício dos direitos sexuais e reprodutivos: em recortes, o processo de viver de um grupo de mulheres de classes populares. Texto contexto-enferm. 2007; 16(1)1586-94.

12. Carvalho LEC, Cecatti JG, Osis MJD, Sousa MH. Número ideal de filhos como fator de risco para laqueadura tubária. Cad. Saúde Pública. 2004; 20(6): 1565-74.

13. Moreira MHC, Araújo JNG. Planejamento familiar: autonomia ou encargo feminino?. Psicol. estud. 2004; 9(3): 389-8.

14. Carvalho MLO, Schor N. Motivos de rejeição aos métodos contraceptivos reversíveis em mulheres esterelizadas. Rev. Saúde Públ. 2005; 39(5) : 788-94.

15. Martins LBM, Costa Paiva L, Osis MJD, Sousa MH, Neto AMP, Tadini V. Conhecimento sobre métodos anticoncepcionais por estudantes adolescentes. Rev. Saúde Públ. 2006;40(1): 57-64.

16. Moura ERF, Silva RM, Galvão MTG. Dinâmica do atendimento em planejamento familiar no Programa de Saúde da Família no Brasil. Cad. Saúde Pública. 2007; 23(4): 961-70.

17. Berlofi LM, Alkim ELC, Barbieri M, Guazzelli CAF, Araújo FF. Prevenção da reincidência de gravidez em adolescentes: efeitos de um Programa de Planejamento Familiar. Acta paul. enferm.. 2006; 19(2): 196-200.

Artigo recebido em 22.11.07.

Aprovado para publicação em 31.03.09. 